\title{
Evolution of Urban Flooding in China
}

\author{
Dianyi Yan ${ }^{1,2}$, Jiahong Liu ${ }^{2,3,4}$, Weiwei Shao ${ }^{2,4}$, and Chao Mei ${ }^{2}$ \\ ${ }^{1}$ Yangtze River Eco-Environment Engineering Research Center, \\ China Three Gorges Corporation, Beijing 100038, China \\ ${ }^{2}$ State Key Laboratory of Simulation and Regulation of Water Cycle in River Basin, \\ China Institute of Water Resources and Hydropower Research, Beijing 100038, China \\ ${ }^{3}$ School of Transportation and Civil Engineering \& Architecture, \\ Foshan University, Guangdong, 528000, China \\ ${ }^{4}$ Engineering and Technology Research Center for Water resources and Hydroecology \\ of the Ministry of Water Resources, Beijing 100038, China
}

Correspondence: Jiahong Liu (liujh@iwhr.com)

Published: 16 September 2020

\begin{abstract}
With the rapid development of cities in China, urban flooding becomes a growing problem, which not only affect the living quality of the public, but also threatens urban safety. Recently, urban flooding is attached more attention. By analyzing and summarizing urban flooding data from recent decades, which includes frequency, scope of influence, and losses, the causes and status quo of urban flooding problems in China is generalized from varied perspectives of urban climate change, urban planning, urban construction, urban management and policy. The data shows that the number of cities suffered from urban flooding increased by approximately $30 \%$ since 1980s, while the average frequency of urban flood increased from nearly 1 time in every 2 years to more than 3 times per year in some major cities that face serious urban flooding risks. Even for those cities located in west-northern and semi-arid regions, such as Taiyuan in Shanxi province, they also suffered from urban flooding. Prevention and control measures like the constriction of sponge city, the upgrade of drainage system, and the promotion of relative policies are suggested.
\end{abstract}

\section{Introduction}

Throughout history, flooding took place frequently in China. As recorded, 1092 times of flooding has happened in China from 206 BC to 1949 (Zhang et al., 1992). Among all the flooding events, urban flooding, which is a phenomenon occurs when the amount of rain precipitated is more than the drainage capacity of cities (Konrad, 2016), becomes a kind of disasters that affect cities in China the most. With the rapid development of these cities, urban flooding becomes a growing problem. Recently, urban flooding has occurred in more than $60 \%$ of cities in China; approximately 140 cities were flooded for more than 3 times between 2008 and 2010, which reflects the problems of outdated infrastructure construction and incomplete city functions (Huang, 2013; Zhang et al., 2016). Begin from 2000, 200 times of urban flooding happens in China every year in average (Zhang et al., 1992), which severely influences the living quality of the public and causes loss of life and property; in addition, it also threatens urban safety. The status quo of urban flooding in China is that heavy rainstorm causes severe stagnant water on the road, and the major problems it generates include washing away buildings and public utilities, leading to traffic snarls, flooding places like parking lots and subway stations, causing cable breakdown for water supply, electricity and telecommunication, and creating social panic. As a result, more attention is attached to urban flooding in China now.

\section{Facts of flooding events in China}

Before 2006, there were no clear record for urban flooding in China. On the contrary, some data of flood was collected carefully. Based on the "Bulletin of Flood and Drought Disaster in China (2007-2016)" (MWR, 2007-2016), the scope 


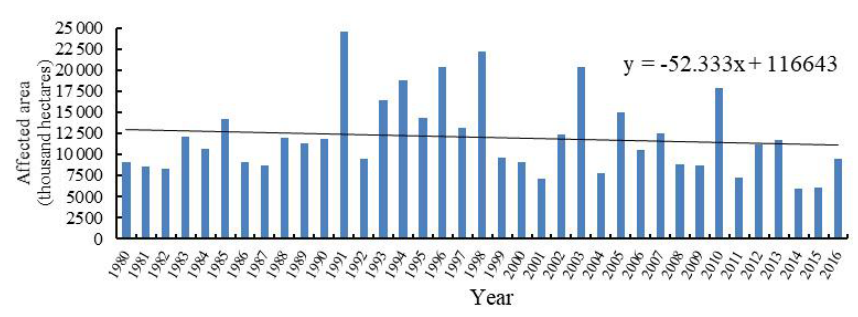

Figure 1. Data of flood-affected area from 1980-2016 (MWR, 2007-2016).

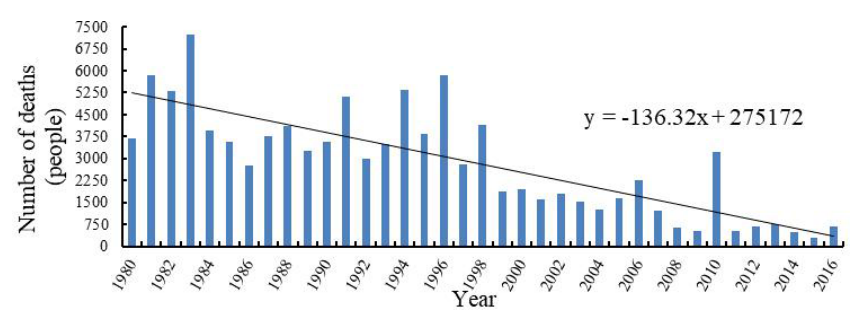

Figure 2. Number of deaths caused by flood from 1980-2016 (MWR, 2007-2016).

of flood, which includes areas affected by flood and the number of deaths, and losses caused by flood, which includes the number of collapsed buildings and direct economic losses in China from 1980 to 2016 which can be summarized as follows.

The average area that affected by flood in 1980s was approximately 10.4 million hectares, and the average area that affected by flood from 2010 to 2016 was around 9.9 million hectares. By adding a trendline on the graph (Fig. 1), the area affected by flood in China turns to slowly decrease from 1980s to 2016.

As shown in Fig. 2, it is obvious that the number of deaths decreased relatively rapidly from 1980 s to 2016 . In average, there are about 4349 people died per year because of flood in 1980s, and 954 people died per year from 2010 to 2016, which can be a strong evidence to show the successful development of economic society in China because the government has strove to create a much safer living environment for the public.

The change of the number of collapsed buildings (Fig. 3) is similar as the change of the number of deaths (Fig. 2). The number of collapsed buildings caused by flooding was reduced from 1980s to 2016. The average numbers of collapsed buildings in 1980s and from 2010 to 2016 are 154 and 70 buildings, which strongly proves that the construction quality in China has soared.

Due to the information gap before 1990, only the data of direct economic losses caused by flood from 1990 to 2016 are in record. The trend of the change of direct economic losses caused by flood in these 27 years keeps raising. Nowadays, economy is highly concentrated in cities. Almost half of these economic losses were contributed by cities. It was

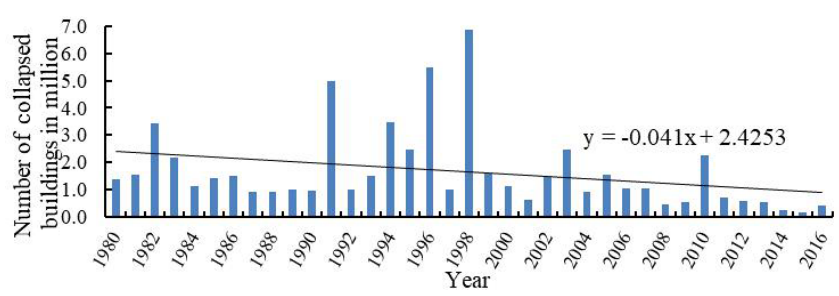

Figure 3. Number of collapsed buildings after flood from 19802016 (MWR, 2007-2016).

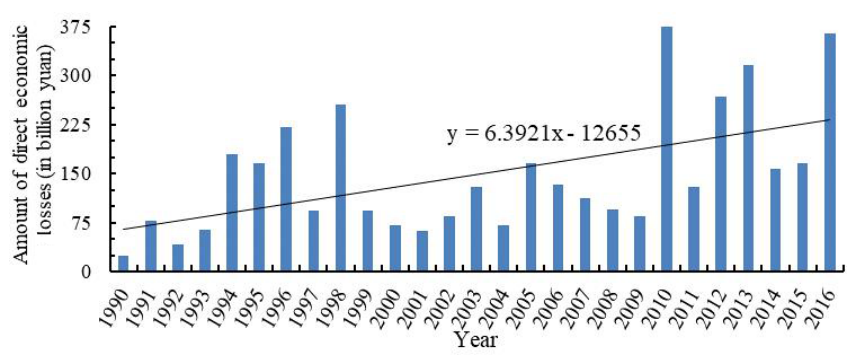

Figure 4. Direct economic losses caused by flood from 1990-2016 (MWR, 2007-2016).

proved that the frequency of urban flooding increased from nearly 1 times in every 2 years to more than 3 times per year in some major cities (Z. Zhang et al., 1992; J. Zhang et al., 2016).

To explore the potential relationship, the data of floodaffected area is adjusted by a factor of 45 , the data of deaths and direct economic losses caused by flood is adjusted by a factor of 10. As shown in Fig. 5, begin from 1990, the trend of the change of flood-affected area, deaths, collapsed buildings, and direct economic losses caused by flood were similar, which indicates that population and economics in China are highly concentrate in places vulnerable to floods, and there was a strong chain reaction between factors displayed in Fig. 5.

According to the collection of flood and drought distribution data from 1980 to 2000 (Zhang, 2003), the number of cities that are potential to be flooded is summarized as shown in Fig. 5, which covered the whole range of China and included data collected from 120 sites, but it was not updated after 2000.

Due to the lack of data collection of exact number of cities where urban flooding has happened in 1980s, the trend of increasing number of flooded cities can be roughly estimate by data displayed in Fig. 6. By applying a trendline, the average number of potential flooded cities in 1980s is calculated as 37 , and the average number of potential flooded cities from 2010 to 2017 is calculated as 48 , which indicates that the number of potential flooded cities increased by approximately $30 \%$ from 1980 s to now.

Begin from 2006, the Ministry of Water Resources of the People's Republic of China (MWR) began to collect the 


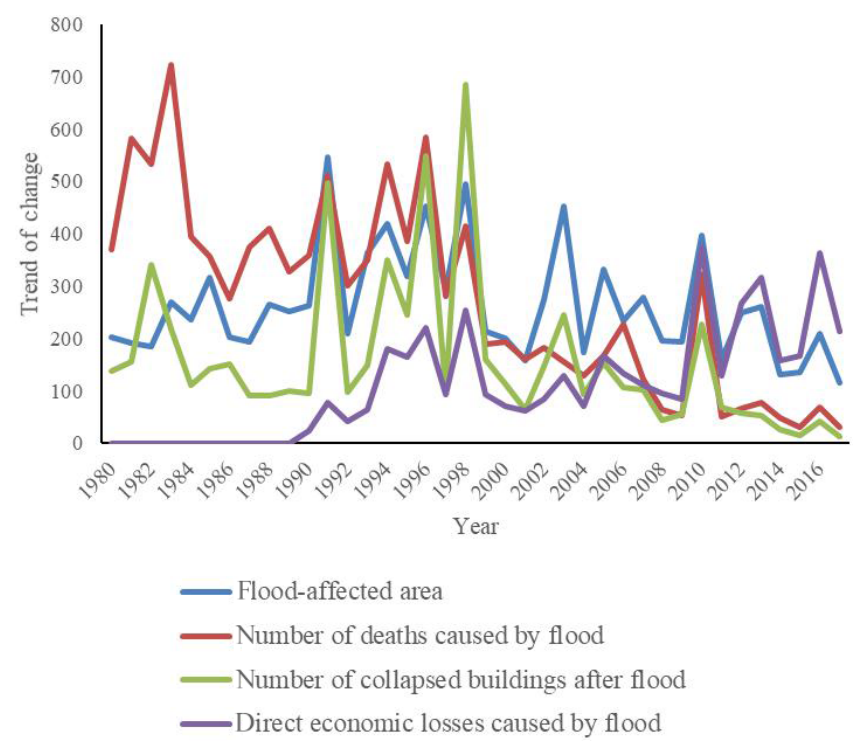

Figure 5. Trend of change (MWR, 2007-2016).

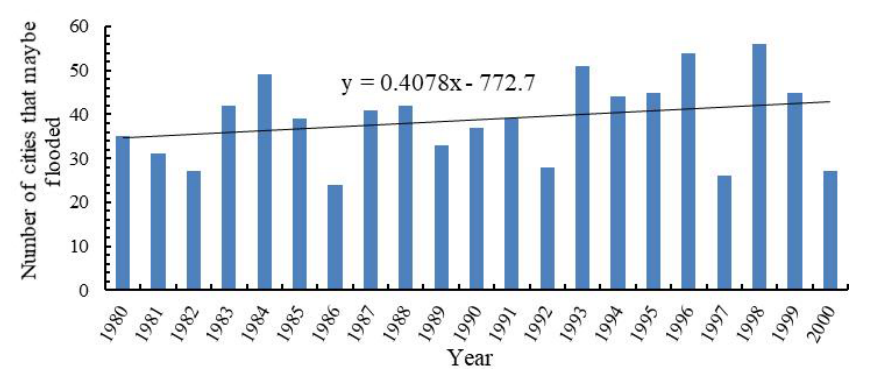

Figure 6. Number of cities that have potential to be flooded (Zhang, 2003).

number of cities that were flooded in each year. Data from 2006 to 2016 is shown in Table 1 . There are over 650 cities in China. As recorded by MWR, approximately $25 \%$ of cities in China were flooded in each year from 2006 to 2016. Even for those cities located in west-northern and semi-arid regions, such as Taiyuan in Shanxi province, they also suffered from urban flooding. Thus, urban flooding is become as one of the most urgent problems in China right now.

\section{Causes of urban flooding in China}

With further development of China's reform and opening up, the urbanization rate in China changed from $10.64 \%$ in 1949 to $57.4 \%$ in 2016, and it was predicted to be $75 \%$ in 2050 (National Bureau of Statistics of the People's Republic of China, 2017). Although the rapid development of cities brings people a better living environment, it also created some problems that affect the living quality of people. One of the problems that people in China have paid more attention on is urban flooding, and this problem is caused by
Table 1. Data of Flooded Cities from 2006 to 2016 in China (MWR, 2007-2016).

\begin{tabular}{cr}
\hline Year & $\begin{array}{r}\text { Number of } \\
\text { Flooded } \\
\text { City* }\end{array}$ \\
\hline 2006 & 118 \\
2007 & 109 \\
2008 & 115 \\
2009 & 136 \\
2010 & 258 \\
2011 & 136 \\
2012 & 184 \\
2013 & 243 \\
2014 & 125 \\
2015 & 168 \\
2016 & 192 \\
\hline *It includes county-level \\
cities, prefecture-level cities, \\
and municipalities.
\end{tabular}

factors in five major aspects, which are geographic position and urban climate, urban planning, urban construction, urban management, and policy.

\subsection{Geographic Position and Urban Climate}

\subsubsection{Geographic Position (Zhang et al., 1992)}

China is located in the east coast of the Eurasia, so monsoon circulation has a great influence on the climate in the country. Most of the major cities in China are seated close to river bank, estuarine, or coastal, and some of the other cities are distributed in places like intermountain basin. Thus, once there were floods, these cities are easy to be drowned, and the urban order would be easy to be disrupted.

\subsubsection{Urban Climate (Zhang et al., 2016)}

Most of buildings in cities are made from reinforced concrete. Those buildings have a specific heat that is much lower than greenbelts, which means that greenbelts can absorb more heat than buildings. In the other words, buildings will increase temperature in cities more than greenbelts. In addition, buildings always block wind, which causes the temperature inside cities is always 1 to $3^{\circ} \mathrm{C}$ higher than the temperature in rural area, which makes cities like an island that is full of heat. This phenomenon is named as urban heat island effect (EPA). Coupling with those air pollution particles, the amount of rainfall condensation nucleus is increased. As a result, the frequency of heavy rainstorm in cities significantly soars as cities develop faster, which creates another phenomenon called urban rain island effect. Take Shanghai as an example, it was proved that the amount of annual precipitation has increased by $5 \%$ in Shanghai than before, and the total precipitation volume and frequency has raised more 
than $10 \%$. Combined with factors from urban planning, construction, management and policy aspects, urban flooding becomes a common urban disaster in China.

\subsection{Urban Planning}

One of the salient problems that China's urban planning has is that people focus more on what to do on the ground instead of caring about what happens under the ground. Fancy buildings and advanced infrastructure construction are visible, and it is easy for people to notice the benefits these facilities can bring to the society. However, on the contrary, the significance of the function of drainage system is always ignored because it is indiscernible. The design of drainage system in China's cities is lack of foresight, the capacity was designed mainly based on the average precipitation at the time when the system was built. In average, the flood control standard for drainage system in most of cities in China is aim to reduce runoff caused by urban flooding that may happen in every one to two years. On the contrary, cities in developed country like the United States, Japan, and France have a much higher flood control standard (Tencent News Encyclopaedia, 2016). The flood control standard for drainage system in New York is for preventing flood that may happen in every 10 to 15 years. As for Tokyo, the drainage system was designed for flood that may occur in every 5 to 10 years. As for Pairs, it was designed for flood that may take place in every 5 years. What is more, when roads in cities were upgraded, the increasing demand of drainage capacity was not fully considered, most of drainage facilities were not synchronously upgraded. Meanwhile, some original facilities even got damaged. Besides, aged pipe in the drainage system is another urgent problem (Yang, 2011). Due to the high frequency of heavy rainstorm, the amount of rain water goes into the drainage system is always exceed its capacity, which directly leads to severe stagnant water on the ground. When the situation gets worse, urban flooding occurs.

Except for problems raised by drainage system, the damage of natural environment is another factor that leads to urban flooding. In the past, people did not have the awareness of the importance of green environment. Ditches and ponds were used to play a significant role on water division and absorption; however, they were filled into roads or buildings. Along with the disappearance of ditches and ponds, cities become fragile in terms of floods. Combined with underdeveloped drainage system, negative effects brought by urban flooding becomes increasingly worse in China.

\subsection{Urban Construction (Li, 2013)}

With the acceleration of urbanization, the surface hardening rate raises, the area of impervious surface grows in places like rooftop and outdoor parking lots. These impervious surfaces, which were made from materials like cement or asphalt, prevent rainwater and snowmelt infiltrating into the ground. It directly increases the surface runoff coefficient (U.S. Geological Survey). The higher the surface runoff coefficient is, the less water can be absorbed by the ground. Furthermore, compared with greenbelts, the construction of roads and buildings significantly reduces the roughness coefficient of the ground, which shortens the concentration time of surface runoff (Zhang et al., 2016). In addition, some construction processes block brooks. Plenty of roads, railways, buildings even occupied lands that were used to be water bodies like rivers or lakes without considering sustainable development of cities. All these factors severely affect the drainage capacity in cities in China.

\subsection{Urban Management (Li, 2013)}

Urban management, especially for drainage management, is weak in most of cities in China. There is no sound urban flooding management department, and the existing method for management is relatively backward. What is more, there is no real-time monitoring system for urban flooding. Thus, people cannot receive precisely information when urban flooding occurs. Coupled with the lack of administrative staff for drainage facilities and weak management system, urban flooding cannot be timely controlled. Besides, the maintenance of drainage system is always not in time. Funding is not enough. Additionally, the drainage equipment is backward when compared with cities in some developed countries.

\subsection{Policy (Liu, 2016)}

In China, there is a regulation called "Land Finance", which allows local governments to sell land-use right for fiscal expenditure. This regulation accelerates the reduction of natural surface area with great flood discharging function. Those surface areas that is low-lying and easy to be waterlogged are especially cheap, the demolition of these areas is less difficult, and the cost recovery will be faster. When compared with the low price of these lands, the potential risk of urban flooding is ignored. Besides, the financial investment from the central government for drainage pipelines is insufficient. Approximately $90 \%$ of the investment is from local government. As the local government's debts grows, it turns arduous for local government to invest more for urban flooding preventing work.

\section{Measures to prevent future urban flooding in china}

\subsection{Reinforcement from Government}

Drainage system is one of the critical indispensable infrastructures in cities. Nowadays, water surface ratio and seepage rate of grounds keep decreasing. Along with an increasing frequency of heavy rainstorm, the capacity of most 
build-up drainage systems in China cannot afford the actual amount of water input due to less governmental investment and aged pipelines (Jiang, 2011). Thus, both central government and local governments must reinforce the construction of drainage systems in cities and increase governmental input to reduce the frequency of urban flooding. Besides, existing urban flooding related standards and regulations are just on a technical level. When relative departments plan to supervise the planning and construction of infrastructures, it is lack of legal ground. Therefore, laws related to urban drainage and urban flooding prevention must be established based on China's national conditions. In the United States, some states announced an ordinance which regulates that the flow of rainwater in newly developed area must not exceed its original flow before this area was developed. It means that local governments must avoid the excessive flow of rainwater by developing and improving drainage facilities, and it also enforces governments to increase the financial input in this field (Li, 2013).

\subsection{Improvement of Urban Planning for Newly Developed Area}

The major reason why urban flooding recently turns much easier to occur in China is mainly because that nowadays most of cities are lack of resilience, which means that cities cannot automatically mitigate problems by themselves (Wang et al., 2015). During construction and development, cities lost their ecological functions because roads were covered by impervious material like cement or asphalt, and lakes and rivers were filled for farmland or buildings. Thus, as for future urban planning for newly develop area, ecological rehabilitation should be the priority. With outstanding ability to store floodwater and drain flooded fields, existing watercourse, ditches, and ponds should be protected instead of being filled for more ground area for urban construction. Large low-lying land could be developed as wetland park. In proper area, impounding reservoir could be established to optimal utilize underground space. When designing roads, hardening area should be reduced. Instead of applying cement or asphalt to cover the ground, pervious material must be applied to increase water and air permeability of the road and reduce stagnant water on the ground. Moreover, it is a must to expand green areas because they not only can beautify the environment but also can absorb and store stormwater to assist to prevent urban flooding (Yang, 2011; Liu, 2016). In addition, when preparing flood protection measures, cities' affordability for floods should be considered and studied for a more precise planning. Besides, although the drainage capacity depends on drainage system, but it is also affected by coordination work between planning department, department of water, department of municipal administration, and department of urban construction. Each involved department should establish a sound operating network. Instead of designing drainage system in cities in a district level, it should be taken into full account as a whole to avoid the unbalance between drainage capacity and actual amount of stormwater needed to be discharged into the system $(\mathrm{Li}, 2013)$. Most importantly, design return period of urban flooding must be expanded because most of drainage systems were design for flood that may happen only in every 20 years (Yang, 2011), which is extremely not enough for recent precipitation condition. As for cities where people are living now, problems left over by history, such as substandard drainage system, should be solved and improved properly.

Another cause of frequent urban flooding is due to the lack of financial support and attention for the construction of underground facilities. Therefore, when reforming or developing new areas for human activity, underground construction must be put in the first place.

\subsection{The Do's and Don'ts for Urban Construction}

Most of urban embankments in China have a long history with low quality, and their foundations were not properly treated when they were built (Zhang et al., 1992). Besides, the average flood control standard is relatively low in China. As a result, when floods take place, it is easy for river to burst its banks and cause severe urban flooding, so it is vital to strengthen the construction of floodwall and embankments. Additionally, the expansion of cities increases the risk of urban flooding. During urban construction, water permeability of underlying surface must be ensured, and the upgrade of existing drainage system in old neighbourhoods should be concurrently upgraded. Besides, underground space should be fully utilized. Reservoir could be a proper option to build under the ground. During construction process, permeable material should be fully applied. When choosing construction materials and plants for green area like gardens and wetlands, local precipitation condition need to be fully considered.

\subsection{Improvement of Management and Early Warning System}

To effectively remit the negative influences caused by urban flooding, drainage management must be taken seriously. As time goes by, those pipelines for drainage gradually become aged, and their capacity cannot meet the actual amount of rainwater or snowmelt that needs go into them. Thus, it is significant to renovate old pipelines, especially in those old districts. As for those intricate pipes, they must be located systematically and scientifically so that when problems, such as leakage, occur in these pipes, it is easy to timely find out where it happens and come up with proper solutions. Besides, when heavy rainstorm occurs, all the drainage system must be operated instantly to drain as much water as it can. What is more, regular clean-up must be done for drainage system to avoid unnecessary blocking, especially for the sewers, watercourse, and river channels. As for natural water bodies, it must be prohibited to fill them for more land to 
use or dump trash into them to en smooth drainage when heavy rainstorm occurs. Another important measure here is the setup of advanced early warning system. The government must attach importance to response mechanism (Jiang, 2011). Meteorological department should forecast and forewarn the happening of heavy rainstorm and instantly send feedback information to the other involved departments. Water department must activate necessary equipment, such as water suction pumps, for drainage system in time. Transportation department must be ready to disperse excess traffic with more traffic management coordinators. Public security department should take the responsibility to keep order in the streets to avoid over-crowdedness. As for those locations that is easy to be flooded, such as underground parking lots, drainage equipment like water suction pumps and sandbag should be prepared in advance. Moreover, before heavy rainstorm comes, water level in controllable rivers and canals should be lowered to assist to drain and store water (Yang, 2011). In addition, the corporation between government departments and social media should be strengthened. Realtime update of urban flooding condition in cities through text message, radio, and television should be promoted for the public.

After heavy rainstorm, all relevant government departments should check each drainage system and collect statistic data to summarize if there were anything need to be improved for a more effectively and quickly response to future urban flooding. As for places that suffered from severe flood, it should be insisted on the accountability within relative departments.

\subsection{Construction of Sponge City (Citiscope, 2016; Go Chengdu, 2015)}

In China's the 12th and 13th five-year plans, they both indicated that the construction of sponge city should play a significant role in China's future development. There are 30 pilot sponge cities in China right now. "Sponge city" means to reform cities as sponges to absorb and store water. The most important components in sponge cities are green buildings, permeable road surface, bio-retention facilities, wetlands, lakes, rivers, rain gardens, and forests. The construction of sponge city can promote the water permeability of roads, expand green areas, increase the utilization rate of underground space, reduce urban heat island effect to lower urban air temperature, raise the utilization rate and promote purification of rainwater, decrease the occurrence rate of urban flooding, and raise city's resilience (Liu, 2016). Due to the rainwater circulation system created by the construction of sponge city, when heavy rainstorm occurs, each component in a sponge city can help to reduce the amount of surface runoff, which can effectively prevent urban flooding.

\subsection{Rising Awareness of Urban Flooding (Jiang, 2011)}

Urban heat island effect is one of the major causes of heavy rainstorm. Artificial heat emission is the major factor that aggravates this effect. Thus, Citizens should raise the awareness of reducing artificial heat emission. Instead of driving personal cars, public transportation should be advocated to reach low-carbon emission. Besides, citizens' social sense should be raised as well. Everyone should contribute to the prevention of urban flooding.

\subsection{Learning from Successful Foreign Experience}

Developed countries, such as the United States, France, and Japan, are ahead of the curve in urban flooding prevention area. The United States have announced an ordinance which regulates that the flow of rainwater in newly developed area must not exceed its original flow before this area was developed. France has developed sophisticated largescale drainage system and effective early warning system for flooding risks, which distinctly decreased the threat of urban flooding. Japan used 14 years, from 1992 to 2006, established the Metropolitan Area Outer Underground Discharge Channel, which is also known as "The Underground Temple". In this huge drainage system, 59 18-meter-long massive pillars hold a huge reservoir with a width of $78 \mathrm{~m}$ and a length of $177 \mathrm{~m}$, and this system can pump up to $200 \mathrm{t}$ of water into the Edo River per second for preventing urban flooding in Tokyo (Risa, 2017). China should learn from their experience to establish proper systems or laws to mitigate the negative influences brought by urban flooding to cities and the public.

\section{Conclusions}

Urban flooding has strongly affected people's livelihood and social development in China. Although the areas influenced by urban flooding, the number of deaths, and the number of collapsed buildings keeps decreasing from 1980s to now, the direct economic losses and the number of flooded cities grows. The number of cities where urban flooding has taken place is approximately $25 \%$ of the total number of cities in China, so urban flooding is still an urgent problem needed to be solved. Close-to-water geographic position, warming urban climate, unbalanced urban planning and construction, unsubstantial urban management, and deficient policies are the major factors that cause frequently urban flooding in China. The most significant tasks are to upgrade old drainage systems and promote the construction of sponge city to increase cities' resilience to mitigate urban flooding in China. Besides, proper investment and policies are also required.

Data availability. Data analyzed in this article is from "Bulletin of Flood and Drought Disaster in China (2007-2016)", the data of the scope of flood, which includes areas affected by flood and the 
number of deaths, and losses caused by flood, which includes the number of collapsed buildings and direct economic losses in China from 1980 to 2016 was applied in the analysis. All the data are open accesses, and the URL (in Chinese) is http://www.mwr.gov.cn/sj/ tjgb/zgshzhgb/, last access: 20 July 2017.

Author contributions. DY is the major author of this paper, this author contributed to conceive the whole article, collect and analyze data, and write the article. JL contributed significantly to analysis and manuscript preparation. WS contributes to perform the analysis with constructive discussions. Chao Mei contributes to embellish the article.

Competing interests. The authors declare that they have no conflict of interest.

Special issue statement. This article is part of the special issue "Hydrological processes and water security in a changing world". It is a result of the 8th Global FRIEND-Water Conference: Hydrological Processes and Water Security in a Changing World, Beijing, China, 6-9 November 2018.

Acknowledgements. This study was supported by the Chinese National Natural Science Foundation (nos. 51522907 and 51739011), the National Key Research and Development Program of China (2016YFC0401401), and the Research Fund of the State Key Laboratory of Simulation and Regulation of Water Cycle in River Basin, China Institute of Water Resources and Hydropower Research (no. 2017ZY02).

Financial support. This research has been supported by the Chinese National Natural Science Foundation (grant nos. 51522907 and 51739011)

\section{References}

Can "sponge cities" solve China's urban flooding problem?, Citiscope, available at: http://citiscope.org/story/2016/ can-sponge-cities-solve-chinas-urban-flooding-problem, last access: 28 July 2016.

Chengdu plans to become "sponge city", Go Chengdu, available at: http://www.gochengdu.cn/news/Highlights/ chengdu-plans-to-become-sponge-city--a1287.html, last access: 2 March 2015.
Effects of impervious surfaces on streamflow, U.S. Geological Survey, available at: https://water.usgs.gov/edu/impervious.html, last access: 2017.

Heat Is land Effect, U.S. Environmental Protection Agency, available at: https://www.epa.gov/heat-islands, last access: 2017.

Huang, J.: The influence of climate change like flooding on urban roads drainage and the measures, Urban Construction Theory Research, 28, 1-4, 2013.

Jiang, D.: Major causes of urban flooding and countermeasures in China, Commercial Culture, Academic Edition, 3, p. 351, 2011.

Konrad, C. P.: Effects of urban development on floods, Department of the Interior, U.S. Geological Survey, available at: https://pubs. usgs.gov/fs/fs07603/, last access: 29 November 2016.

Li, J.: Causes of urban flooding in larger and medium-sized cities in China and the analysis of countermeasures, Urban Construction Theory Research, 2, 123-126, 2013.

Liu, J.: The urban expansion problems caused by frequent urban flooding in China, available at: http://finance.sina.com.cn/roll/ 2016-08-04/doc-ifxutfyw0531051.shtml, last access: 4 August 2016.

National Bureau of Statistics of the People's Republic of China, The People's Republic of China national economic and social development statistical bulletin in 2017, available at: http://www. stats.gov.cn/tjsj/zxfb/201802/t20180228_1585631.html, last access: 28 February 2018.

Risa, Y.: "Beauty" of Japan's huge concrete utilities pulls in tourists, The Asahi Shimbun, available at: http://www.asahi.com/ajw/ articles/AJ201703100008.html, last access: 10 March 2017.

MWR: The Ministry of Water Resources of the People's Republic of China, Bulletin of Flood and Drought Disaster in China, 20072016.

Wang, W., Wang, Q., Lin, H., Gong, D., and Zhang, S.: The review of China's urban flooding research and the outlook, Urban Problems, 5, 24-28, 2015.

Why is Wuhan always flooded?, Tencent News Encyclopaedia, available at: http://news.qq.com/cross/20160706/48K6xRR1. html $\{\#\} 0$, last access: 6 July 2016.

Yang, L.: Reasons of urban waterlogging and its countermeasures, Anhui Architecture, 1, 127-158, 2011.

Zhang, D., Xiaoquan, L., and Youye, L.: The renewal of "the distribution data collection in recent 500 years in China" (1993-2000), J. Appl. Meteorol. Sci., 14, 379-388, 2003.

Zhang, J., Wang, Y., He, R., Hu, Q., and Song, X.: Discussion on the urban flood and waterlogging and causes analysis in China, Adv. Water Sci., 27, 485-491, 2016.

Zhang, Z., Wang, C., and Zhao, Z.: On city flood cause in China and reduction measures, China Population Resources and Environment, 2, 21-24, 1992. 